Article

\title{
Anti-inflammatory Activity of Hautriwaic Acid Isolated from Dodonaea viscosa Leaves
}

\section{David Osvaldo Salinas-Sánchez ${ }^{1}$, Maribel Herrera-Ruiz ${ }^{2}$, Salud Pérez $^{3}$, Enrique Jiménez-Ferrer ${ }^{2}$ and Alejandro Zamilpa ${ }^{2, *}$}

1 Biodiversity and Conservation Research Center. (UAEM), Av. Universidad 1001, Col. Chamilpa, Cuernavaca 62209, Morelos, Mexico; E-Mail: osval1671@hotmail.com

2 Biomedical Research Center of the South (IMSS), Argentina 1, Col. Centro, Xochitepec 62790, Morelos, Mexico; E-Mails: edanae10@yahoo.com.mx (M.H.-R.);

enriqueferrer_mx@yahoo.com (E.J.-F.)

3 Department of Biological Systems, (UAM-Xochimilco), Calzada del Hueso 1100, Col. Villa Quietud, México D.F. 04960, Mexico; E-Mail: msperez46@yahoo.com.mx

* Author to whom correspondence should be addressed; E-Mail: azamilpa_2000@yahoo.com.mx; Tel.: +52-777-361-215-5.

Received: 10 February 2012; in revised form: 10 March 2012 / Accepted: 15 March 2012 / Published: 10 April 2012

\begin{abstract}
The aim of this study was to identify an anti-inflammatory compound from D. viscosa leaves. The structure of this bioactive substance was elucidated by IR and NMR studies, which indicated that this natural product corresponds to hautriwaic acid (HA). This diterpene exhibited good anti-inflammatory activity in 12-O-tetradecanoylphorbol 13-acetate (TPA) mice ear edema models by applications at doses of $0.25,0.5$ and $1.0 \mathrm{mg} / \mathrm{ear}$ (60.2, 70.2 and 87.1\% inhibition, respectively); additionally Dodonaea viscosa dichloro-methane extract (DvDE) displays a $97.8 \%$ anti-inflammatory effect at $3 \mathrm{mg} / \mathrm{kg}$. Multiple applications of DvDE at doses of $100 \mathrm{mg} / \mathrm{kg}$ on TPA mice ear edema inhibited the edema-associated inflammation by $71.8 \%$, while $\mathrm{HA}$ at doses of $15 \mathrm{mg} / \mathrm{kg}$, reduced edema to $64 \%$ and indomethacin $40 \%$.
\end{abstract}

Keywords: anti-inflammatory activity; Dodonaea viscosa; hautriwaic acid; TPA 


\section{Introduction}

Inflammation is implicated in several chronic-degenerative diseases like cancer, diabetes and hypertension. These health problems cause high mortality and morbidity levels around the world. Other inflammation-related diseases like infections by bacteria, virus and protozoa or autoimmune diseases like arthritis or Alzheimer's are relevant. The main treatments used to prevent or minimize the progression of inflammation include non-steroidal anti-inflammatory drugs (NSAIDs) and corticosteroids, but they are known to have deleterious side effects [1]. Traditional medicine has been used to address human health demands and nowadays it could be considered as the most important source of new anti-inflammatory compounds [2]. The overexposure to the irritant substance 12-O-tetradecanoylphorbol 13-acetate (TPA) induces oxidative stress, cutaneous inflammation, and epidermal hyperplasia because it increases the proliferation of keratinocytes and the production of the pro-inflammatory cytokine tumor necrosis factor-alpha (TNF- $\alpha$ ) and the formation of leukotrienes (LTB4), which result in an increase of vascular permeability and neutrophil influx [3]. Chronic TPA application (five times in 10 days) in mice induces a prolonged inflammatory reaction characterized by the increase in mice ear thickness, infiltration of inflammatory cells (polymorphonuclear leukocytes), and epidermal hyperplasia [4]. This toxic compound induces the release of interleukin (IL)-1 $\alpha$ from the keratinocytes and also from the de novo genetic expression of cytokines [5]. Some anti-inflammatory drugs are the first choice in treatment of this last medical disorder. Dodonaea viscosa is widely used by local healers in the Reserva de la Biosfera Sierra de Huatla (REBIOSH), located in Morelos, Mexico, for the treatment of inflammation, pain, and rheumatism [6]. Several pharmacological studies have demonstrated the anti-diarrheal, antibacterial, analgesic, antiviral, antiulcer, antioxidant and anti-inflammatory activities of this medicinal plant [7-12]. Previous phytochemical studies indicated that $D$. viscosa contains flavonoid- and terpenoid-type secondary metabolites [13-16]. The objective of the present work was to obtain and identify the most abundant terpene from $D$. viscosa and evaluate its anti-inflammatory properties in both chronic and acute in vivo inflammation models.

\section{Results and Discussion}

DvDE displayed an important anti-inflammatory activity. Open column chromatographic purification of this extract allowed us to obtain an anti-inflammatory terpenoid mixture (F1). Recrystallization of this fraction produced a colorless solid compound that displayed potent anti-inflammatory effects. This purified compound was identified as hautriwaic acid (1, Figure 1) by analysis of its ${ }^{1} \mathrm{H}$ - and ${ }^{13} \mathrm{C}$-NMR and infrared spectroscopy data as it showed similar ${ }^{1} \mathrm{H}$ - and ${ }^{13} \mathrm{C}-\mathrm{NMR}$ signals (summarized in the Experimental section) to this ent-clerodane diterpene, which was previously isolated from this plant [17,18]. Characteristic signals for HA at 2,921, 2,848, 1,652, 1,447 and $870 \mathrm{~cm}^{-1}$ were observed in the IR spectrum. 
Figure 1. Hautriwaic acid.

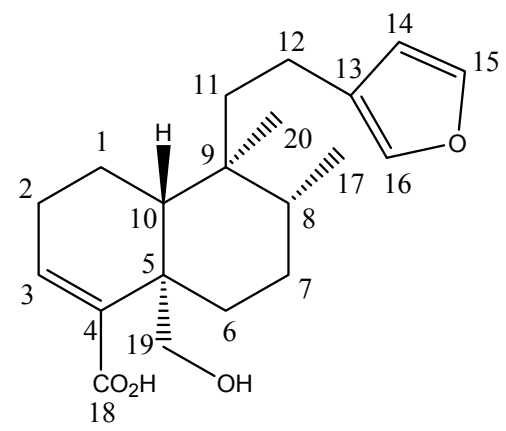

(1)

\subsection{Anti-Inflammatory Activity}

The anti-inflammatory effect of the dichlorometane extract was tested at doses of $3 \mathrm{mg} / \mathrm{ear}$ on a TPA-induced edema model, where it displayed a significant inhibition of $97.8 \%$ of the edema (Table 1).

Table 1. Anti-inflammatory activity of dichloromethane extract (DvDE), Fraction 1 (F1) and indomethacin (Indo) on TPA induced edema model in CD-1 mice.

\begin{tabular}{ccccc}
\hline Substance & Time $(\mathbf{h})$ & Dose $(\mathbf{m g} / \mathbf{e a r})$ & Edema $(\mathbf{m g})$ mean \pm SEM & Edema inhibition (\%) \\
\hline TPA & 6 & --- & $9.88 \pm 0.64$ & --- \\
DvDE & 6 & 3 & $0.21 \pm 0.09 *$ & $97.8 \pm 0.9$ \\
F1 & 6 & 1 & $0.3 \pm 0.10 *$ & $96.9 \pm 1.1$ \\
Indo & 6 & 1 & $0.71 \pm 0.43 *$ & $92.7 \pm 6.2$ \\
\hline \multicolumn{5}{c}{$*<0.05$ in comparison with TPA group. }
\end{tabular}

HA was tested at doses of $0.25,0.5$, and $1.0 \mathrm{mg} / \mathrm{ear}$ on TPA-induced inflammation in CD-1 mouse auricular pavilion and showed percentages of inhibition of inflammation of $60.2,70.2$, and $87.1 \%$ respectively. At doses of $1.0 \mathrm{mg} / \mathrm{ear}$ the activity was similar to that of the positive control indomethacin $(86 \%, 1 \mathrm{mg} /$ ear, Table 2$)$.

Table 2. Ascendant doses evaluation of HA in TPA-induced inflammation model.

\begin{tabular}{ccccc}
\hline Substance & Time (h) & Dose (mg/ear) & Edema (mg) mean \pm SEM & Edema inhibition (\%) \\
\hline TPA & 6 & --- & $9.8 \pm 0.9$ & -- \\
HA & 6 & 0.25 & $3.9 \pm 0.6^{*}$ & $60.2 \pm 6.5$ \\
HA & 6 & 0.5 & $2.9 \pm 0.7 *$ & $70.2 \pm 7.4$ \\
HA & 6 & 1.0 & $1.2 \pm 0.4^{*}$ & $87.1 \pm 4.4$ \\
Indo & 6 & 1.0 & $1.3 \pm 0.8^{*}$ & $86.0 \pm 6.4$ \\
\hline \multirow{4}{*}{$p<0.05$ in comparison with TPA group; HA showed an E max $=97 \%$ of edema } \\
\multicolumn{2}{l}{ inhibition with an $\mathrm{ED}_{50}=0.158 \mathrm{mg}$ /ear. }
\end{tabular}

Bonferroni post-test indicates that both indomethacin results (Tables 1 and 2) were not significantly different. The anti-inflammatory activity of DvDE $(100 \mathrm{mg} / \mathrm{kg})$ and HA $(15 \mathrm{mg} / \mathrm{kg})$ administered via the intraperitoneal route, was demonstrated in a chronic TPA assay. These treatments showed an 
important inhibition of edema 71.8\% (DvDE) and 64\% (HA), respectively. Indometacin (5 $\mathrm{mg} / \mathrm{Kg})$ displayed an edema inhibition of $40 \%$ (Table 3 ).

Some medicinal species with anti-inflammatory activity produce clerodane diterpenes and furanoclerodanes. Baccharis incarum produced a marked anti-inflammatory action in the carrageenan foot edema test, and contains a neoclerodane diterpenoid named bincatriol [19]. Other neoclerodane diterpenes that exert potent anti-inflammatory effect are $E$-isolinaridial and its methyl ketone derivative from Linaria saxatilis [20]. Although hautriwaic acid and other furoclerodane diterpenoids have been isolated from anti-inflammatory species [21,22], this is the first time that this biological effect has been shown for hautriwaic acid. Further studies examining the activity of $D$. viscosa in rheumatoid arthritis and other desease-specific models of inflammation are warranted. Because of that it is pertinent to propose Dodonaea viscosa for testing in rheumatoid arthritis (RA) models.

Table 3. Percentage of inhibition (\%) of the DvDE, HA and indomethacin (Indo).

\begin{tabular}{ccccc}
\hline Substance & Time (day-h) & Dose $(\mathbf{m g} / \mathbf{K g})$ & Edema $(\mathbf{m g})$ mean \pm SEM & Edema inhibition (\%) \\
\hline TPA & $10-6$ & --- & $13 \pm 2.6$ & --- \\
DvDE & $10-6$ & 100 & $3.8 \pm 1.06^{*}$ & $71.8 \pm 8.4$ \\
HA & $10-6$ & 15 & $4.6 \pm 1.03 *$ & $64 \pm 7.9$ \\
Indo & $10-6$ & 5 & $7.8 \pm 0.85 *$ & $40 \pm 6.5$ \\
\hline
\end{tabular}

All treatments were administrated by intraperitoneal (i.p.) via. CD-1 mice were used in this topical TPA induced inflammation test. $* p<0.05$ in comparison with TPA group.

\section{Experimental}

\subsection{General}

12-O-Tetradecanoylphorbol 13-acetate (TPA) and indomethacin (Indo) were purchased from Sigma Chemical Co. (St. Louis, MO, USA). Dichloromethane, acetone, and ethyl acetate were acquired from Mallinckrodt Baker (Phillipsburg, NY, USA). Silica gel 60 and chromatographic plates were obtained from Merck KGaA (Darmstadt, Germany). The infrared spectrum was recorded in solid phase using a Perkin-Elmer Paragon 1000 FT-IR spectrophotometer. NMR spectra were recorded at $298 \mathrm{~K}$ on a Bruker Avance DMX500 spectrometer operated at $500.13309 \mathrm{MHz}$ for ${ }^{1} \mathrm{H}-\mathrm{NMR}$ and $125.77036 \mathrm{MHz}$ for ${ }^{13} \mathrm{C}-\mathrm{NMR}$. ${ }^{1} \mathrm{H}$ - and ${ }^{13} \mathrm{C}$-NMR chemical shifts were reported relative to TMS and $\mathrm{CDCl}_{3}$, respectively.

\subsection{Plant Material}

Dodonaea viscosa was collected at REBIOSH and a sample was deposited at the Herbarium of the Universidad Morelos (HUMO) with registration number: HUMO-26620. Vegetal identification was performed by Juan Carlos Juárez at the Centro de Investigación en Biodiversidad y Conservación (CIByC).

\subsection{D. viscosa (DvDE) Dichloromethane Extract}

The dried and ground material $(1 \mathrm{~kg})$ was extracted with dichloromethane $(5 \mathrm{~L})$ by maceration for 3 days $/ 3$ times. The solvent was eliminated under reduced pressure distillation with a Heidolph rotary 
evaporator. Dried extracts were compared by thin layer chromatography (TLC). Due to their chemical similarity, the extracts were mixed, giving a total yield of $2.03 \%$.

\subsection{HA Purification}

DvDE extract (15.0 g) was fractionated in an open chromatographic column previously packed with $80 \mathrm{~g}$ of silica gel 60 . An $n$-hexane-ethyl acetate gradient system was utilized as mobile phase, starting with $100 \%$ of the solvent of least polarity and finalizing with $100 \%$ ethyl acetate. This process was monitored by thin layer chromatography to afford a terpenoid mixture (F1). This fraction $(8 \mathrm{~g})$ was dissolved in a dichloromethane/acetone mixture $(7: 3,20 \mathrm{~mL})$ resulting in the crystallization of the major component that produced a blue spot in a thin layer chromatographic plate treated with Koumarosky reagent, indicating the presence of a terpene [23] and identified as hautriwaic acid (1): $1.5 \mathrm{~g}$; colorless amorphous powder; m.p. $=175-176.5{ }^{\circ} \mathrm{C}$; IR $\mathrm{v} \max =2,921$, 2,848, 1,652, 1,747, $870 \mathrm{~cm}^{-1} ;{ }^{1} \mathrm{H}-\mathrm{NMR}\left(400 \mathrm{MHz}, \mathrm{CDCl}_{3}\right): \delta 7.35$ (1H, m, H-15), $7.20(1 \mathrm{H}, \mathrm{m}, \mathrm{H} 16)$, 6.67 (1H, t, H-3), 6.25 (1H, m, H-14), 4.14 (1H, d, H-19), 3.68 (1H, d, H-19), 0.87 (3H, d, H-17), 0.76 (3H, s, H20). ${ }^{13} \mathrm{C}-\mathrm{NMR}\left(100 \mathrm{MHz}, \mathrm{CDCl}_{3}\right), \delta 172.13$ (C18), 142.4 (C15), 141.1 (C-4), 138.0 (C-16), 138.0 (C-3), 124.9 (C-13), 110.5 (C14), 64.5 (C19), 45.9 (C-10), 41.5 (C-9), 38.3 (C-5), 38.2 (C-11), 35.8 (C-8), 30.79 (C-6), 26.3 (C-2), 26.2 (C-7), 18.1 (C-20), 17.8 (C-12), 16.5 (C-1), 15.3 (C17).

\subsection{Animals}

We used female CD-1 mice that weighed 25-30 g. Experiments were performed according to the Official Mexican Rule: NOM-062-ZOO-1999 Guidelines (Technical Specifications for the Production, Care, and Use of Laboratory Animals) and international ethical guidelines for the care and use of experimental animals. The experimental protocol was authorized by the Local Health Research Committee (IMSS, Register number: R-2010-1701-33). Mice were maintained at a temperature of $22{ }^{\circ} \mathrm{C} \pm 3{ }^{\circ} \mathrm{C}, 70 \% \pm 5 \%$ of humidity with 12-h light/dark cycles and food/water ad libitum. A control group received acetone as vehicle and indomethacin (Indo) was used as anti-inflammatory positive control.

\subsection{Model of Acute Inflammation in Mice with TPA}

Animal inflammation was induced following the method previously described by Payá [24]. Mice were grouped (eight individuals) and TPA $(2.5 \mu \mathrm{g})$ dissolved in acetone $(20 \mu \mathrm{L})$ was applied on the internal and external surface on the right ear to cause edema. Doses of $3 \mathrm{mg} / \mathrm{ear}$ of each treatment (DvDE extract, F1 and HA) were applied on the ear of each individual. For the isolated compound HA doses of $0.25,0.5$ and $1.0 \mathrm{mg} /$ ear were used. Reference anti-inflammatory drug was administered at $1 \mathrm{mg} /$ ear. All treatments were dissolved in acetone and applied topically on both ears immediately after the administration of TPA. Six hours after administration of the inflammatory agent, the animals were sacrificed by cervical dislocation. Circular sections of $6 \mathrm{~mm}$ in diameter were taken from both: the treated ( $\mathrm{t}$ ) and the non-treated (nt) ears, which were weighed to determine the inflammation. Percentage of inhibition was obtained using expression below:

Inhibition $\%=[\Delta \mathrm{w}$ control $-\Delta \mathrm{w}$ treatment $/ \Delta \mathrm{w}][100]$ 
where $\Delta \mathrm{w}=\mathrm{wt}-\mathrm{wnt}$; wt is the weight of the section of the treated ear; wnt is the weight of the section of the non-treated ear.

\subsection{Model of Chronic Inflammation in Mice with TPA}

We employed the technique described by Lee [25]. Randomized groups of eight mice were formed. A solution with TPA $(2.5 \mu \mathrm{g})$ dissolved in acetone $(20 \mu \mathrm{L})$ was applied topically on alternate days (every $48 \mathrm{~h}$ ) on the right internal and external auricular pavilion to cause inflammation. The studied substances, including DvDE extract $(100 \mathrm{mg} / \mathrm{kg})$ and HA $(15 \mathrm{mg} / \mathrm{kg})$, and Indo $(5 \mathrm{mg} / \mathrm{kg})$ were administered once daily (i.p.) for 10 days; the animals were sacrificed $6 \mathrm{~h}$ after the last day of treatment by cervical dislocation. Central section of $6 \mathrm{~mm}$ in diameter was taken from the right ear (with TPA) and from the left (vehicle); the sections were weighed to determine the percentage of inhibition obtained using the same expression:

$$
\text { Inhibition } \%=[\Delta \mathrm{w} \text { control }-\Delta \mathrm{w} \text { treatment } / \Delta \mathrm{w}][100]
$$

\subsection{Statistical Analysis}

Results from delta weight $(\Delta \mathrm{w}=\mathrm{wt}-\mathrm{wnt})$ are expressed as the mean \pm Standard error of the mean (SEM) and these were analyzed using analysis of variance (ANOVA) and Bonferroni post-test $(* p<0.05)$.

\section{Conclusions}

The DvDE extract of $D$. viscosa at $3 \mathrm{mg} /$ ear displays an important anti-inflammatory activity (97.8\% inhibition of edema). Chromatographic purification of this extract provided a mixture of terpenes (F1) and a colorless crystalline compound that, according to IR and ${ }^{1} \mathrm{H}-,{ }^{13} \mathrm{C}-\mathrm{NMR}$ spectroscopic data, was identified as hautriwaic acid [17,18]. Both F1 and this furoclerodane showed a potent anti-inflammatory effect on and acute model of TPA-induced edema with 96.9 and $87.1 \%$ inhibition at a dose of $1 \mathrm{mg} /$ ear, respectively. This small increase of biological activity of $\mathbf{F} 1$ respect to hautriwaic acid might be due to the fact that F1 may contain some other anti-inflammatory compounds. In the chronic inflammation model, hautriwaic acid displayed $64 \%$ of inhibition of edema at $15 \mathrm{mg} / \mathrm{mg}$. HA showed an $\mathrm{E}_{\max }=97 \%$ of edema inhibition with an $\mathrm{ED}_{50}=0.158 \mathrm{mg} / \mathrm{ear}$. These inhibition values were similar or higher than those of the reference compound indomethacin when it was evaluated in the chronic test. Our study supports the use of $D$. viscosa as an anti-inflammatory treatment.

\section{Acknowledgments}

This work was financially supported by FIS-IMSS (FIS/IMSS/PROT/G11/1930). We are grateful to Ernesto Sánchez Mendoza (UAM-Xochimilco) for his technical assistance. 


\section{References and Notes}

1. Borda, I.T.; Koff, R.S. NSAID. A Profile of Adverse Effects; Hanley and Belfus, Inc.: Philadelphia, PA, USA, 1992.

2. Ogirala, R.G.; Aldrich, T.K.; Prezant, D.J.; Sinnett, M.J.; Enden, J.B.; Williams, M.H. High-dose intramuscular triamcinolone in severe, chronic, life-threatening asthma. N. Engl. J. Med. 1991, 324, 585-589.

3. Calou, I.B.; Sousa, D.I.; Cunha, G.M.; Brito, G.A.; Silveira, E.R.; Rao, V.S.; Santos, F.A. Topically applied diterpenoids from Egletes viscosa (Asteraceae) attenuate the dermal inflammation in mouse ear induced by tetradecanoylphorbol 13-acetate- and oxazolone. Biol. Pharm. Bull. 2008, 31, 1511-1516.

4. Stanley, P.L.; Steiner, S.; Havens, M.; Tramposch, K.M. Mouse skin inflammation induced by multiple topical applications of 12-O-tetradecanoylphorbol-13-acetate. Skin Pharmacol. 1991, 4, 262-271.

5. Murphy, J.E.; Morales, R.E.; Scott, J.; Kupper, T.S. IL-1 $\alpha$, innate immunity, and skin carcinogenesis: The effect of constitutive expression of IL-1 $\alpha$ in epidermis on chemicals carcinogenesis. J. Immunol. 2003, 170, 5697-5703.

6. Dorado, O.; Maldonado, B.; Arias, D.; Sorani, V.; Ramírez, R.; Leyva, E.; Valenzuela, D. Programa de Conservación y Manejo Reserva de la Biosfera Sierra de Huautla, 1st ed. (in Spanish); Comisión Nacional de Áreas Naturales Protegidas: Morelos, Mexico, 2005; pp. 3-4, 33-34, 54, 139-170.

7. Rajamanickam, V.; Rajasekaran, A.; Anandarajagopal, K.; Sridharan, D.; Selvakumar, K.; Rathinaraj, B.S. Anti-diarrheal activity of Dodonaea viscosa root extracts. Int. J. Pharm. BioSci. 2010, 1, 182-185.

8. Anilreddy, B. Preparation, characterization and biological evaluation of some overview of Dodonea viscosa Linn. J. Pharm. Sci. Technol. 2009, 1, 1-9.

9. Khurranm, M.; Khan, M.A.; Hameed, A.; Abbas, N.; Qayum, A.; Inayat, H. Antibacterial activities of Dodonaea viscosa using contact bioautography technique. Molecules 2009, 14, 1332-1341.

10. Pengelly, A. Medicinal Activity of Dodonaea viscosa. A Preliminary Study; RIRDC: Newcastle, Australia, 2008; Available online: http://www.rirdc.gov.au (accessed on 15 June 2011).

11. Khalil, N.M.; Sperotto, J.S.; Manfron, M.P. Antiinflammatory activity and acute toxicity of Dodonaea viscosa. Fitoterapia 2006, 77, 478-480.

12. Alagarsamy, V.; Venket-Narayanan, R.; Thangathirupathy, A.; Amuthalakshmi, S.; Slvakamisundari, P.; Jubie, S.; Syed-Ali, A.K.S.; Suresh, M. Antiinflammatory activity of Dodonaea viscosa Linn leaf extracts. Indian Drugs 2007, 44, 559-560.

13. Sachdev, K.; Kulshreshtha, D.K. Flavonoids from Dodonaea viscosa. Phytochemistry 1983, 22, 1253-1256.

14. Mata, R.; Contreras, J.L.; Crisanto, D.; Pereda-Miranda, R.; Castañeda, P.; Del Rio, F. Chemical studies on mexican plants used intraditional medicine, XVIII. New secondary metabolites from Dodonaea viscosa. J. Nat. Prod. 1991, 54, 913-917. 
15. Ortega, A.; García, P.E.; Cárdenas, J.; Mancera, C.; Marquina, S.; Garduño, M.L.; Maldonado, E. Methyl dodonates a new type of diterpenes with a modified clerodane skeleton from Dodonaea viscosa. Tetrahedron 2001, 57, 2981-2989.

16. Niu, H.-M.; Zeng, D.-Q.; Long, C.-L.; Peng, Y.-H.; Wang, Y.-H.; Luo, J.-F.; Wang, H.-S.; Shi, Y.-N.; Tang, G.-H.; Zhao, F.-W. Clerodane diterpenoids and prenylated flavonoids from Dodonaea viscosa. J. Asian Nat. Prod. Res. 2010, 12, 7-14.

17. Hsu, H.Y.; Chen, Y.; Kakisawa, H. Structure of hautriwaic acid. Phytochemistry 1971, 10, 2813-2814.

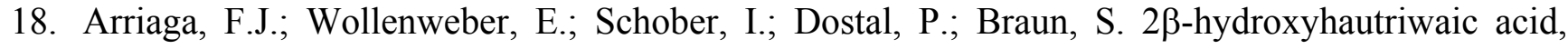
a clerodane type ditepenoid and other terpenoids from three Baccharis species. Phytochemistry 1986, 25, 719-721.

19. Perez, F.; Marin, E.; Adzet, T. The antiinflammatory effect of several composite from South America. Extracts in rats. Phytother. Res. 1995, 9, 145-146.

20. San Martin, A.; Givochich, A.; Castillo, M. Neo clerodane diterpenoids from Baccharis incarum. Phytochemistry 1986, 25, 2829-2831.

21. Benrezzouk, R.; Terencio, M.C.; Ferrándiz, M.L.; San Feliciano, A.; Gordaliza, M.; Miguel Del Corral, J.M.; de la Puente, M.L.; Alcaraz, M.J. Inhibition of human SPLA $_{2}$ and 5-lipoxygenase activities by two neo-clerodane diterpenoids. Life Sci. 1999, 64, 205-211.

22. Missima, F.; da Silva, A.; Nunes, G.A.; Pires, P.; de Sousa, J.P.; Bastos, J.K.; Sforcin, J.M. Effect of Baccharis dracuncufolia D.C (Asteraceae) extracts and its isolated compounds on macrophage activation. J. Pharm. Pharmacol. 2007, 59, 463-468.

23. Wagner, H.; Bladt, S. Plant Drug Analysis. A Thin Layer Chromatography Atlas, 2nd ed.; Springer: Munich, Germany, 2009; p. 362.

24. Payá, M.; Ferrándiz, M.L.; Sanz, M.J.; Bustos, G.; Blasco, R.; Rios, J.L. Study of the antioedema activity of some seaweed and sponge extracts from the mediterranean coast in mice. Phytother. Res. 1993, 7, 159-162.

25. Lee, D.Y.; Choo, B.K.; Yoon, T.; Cheon, M.S.; Lee, H.W.; Lee, A.Y.; Kim, K. Antiinflammatory effects of Asparagus cochinchinensis extract in acute and chronic cutaneous inflammation. J. Ethnopharmacol. 2009, 121, 28-34.

Sample Availability: Samples of the DvDE, F1 and hautriwaic acid are available from the authors.

(C) 2012 by the authors; licensee MDPI, Basel, Switzerland. This article is an open access article distributed under the terms and conditions of the Creative Commons Attribution license (http://creativecommons.org/licenses/by/3.0/). 